\title{
Chemical Composition of Corrosion Products of Rebar Caused by Carbonation and Chloride
}

\author{
Jundi Geng $\mathbb{D}^{\mathbb{D}}$, Junzhe Liu $\mathbb{D}$, Jiali Yan, Mingfang Ba, Zhimin He, and Yushun Li
}

Faculty of Architectural, Civil Engineering and Environment, Ningbo University, Ningbo 315211, China

Correspondence should be addressed to Junzhe Liu; junzheliu@163.com

Received 14 January 2018; Revised 9 April 2018; Accepted 10 April 2018; Published 19 June 2018

Academic Editor: Michael J. Schütze

Copyright (C) 2018 Jundi Geng et al. This is an open access article distributed under the Creative Commons Attribution License, which permits unrestricted use, distribution, and reproduction in any medium, provided the original work is properly cited.

\begin{abstract}
The microstructures of steel bars were studied by X-ray photoelectron spectroscopy (XPS), and the mechanism of corrosion of steel bars under the corrosion factors was elucidated. The results show that the passivation film and corrosive surface of the steel surface in the solution of the chloride-containing salt were coarser and the surface state was denser. The main corrosion products are $\mathrm{FeOOH}$ and $\mathrm{FeO}$. The surface of the steel immersed in the simulated carbonized solution had loose pores. The main components are $\mathrm{FeOOH}, \mathrm{Fe}_{3} \mathrm{O}_{4}$, and $\mathrm{Fe}_{2} \mathrm{O}_{3}$. The surface of the steel bar has a large amount of yellowish brown corrosion products in the simulated carbonization and chloride salt. The surface of the corrosion products was stripped and the main components are $\mathrm{FeOOH}, \mathrm{Fe}_{3} \mathrm{O}_{4}$, and $\mathrm{FeCl}_{3}$, where the content of $\mathrm{FeOOH}$ is as high as $60 \%$. The peak value of iron is gradually increased from the simulated chloride salt solution to the carbonized solution to the combined effect of carbonation and chloride salt; the iron oxide content is increased and corrosion of steel is obviously serious.
\end{abstract}

\section{Introduction}

Chloride salt and carbonization are the main causes of steel corrosion, as evidenced by the failure of a large number of reinforced concrete structures as well as a large number of concrete works under double factor of carbon dioxide and chloride ion [1-4]. In general, the steel surface of the passive film in the steel is stable due to the presence of overbased concrete pore solution. When the outside carbon dioxide and chloride ions infiltrated into the concrete, the $\mathrm{pH}$ of the pore solution decreased and chloride content increased, leading to the destruction of the passive film corrosion [5-9]. Therefore, the main barrier to prevent corrosion of steel is the passive film.

There are many factors affecting the destruction of passivation film, including the surface conditions of steel bars, alloy composition, iron phase composition, and other material factors as well as the permeability of concrete, the concentration of chloride ion, the $\mathrm{PH}$ of solution, temperature and humidity, and other environmental factors [1012]. The properties of the steel passivation film, that is, the thickness, composition, and stability, are influenced by the polarization potential, the polarization time, and the ion concentration in the medium, and the microstructure characteristics of passivation films are related to passivation potential and passivation time. The reason for the corrosion of steel is finally due to the change of the composition and structure of passivation film [13-16]. It can be seen that there is an urgent need to clarify the failure process of passivation film under carbonation and chloride corrosion and clarify the damage mechanism of passivation film of steel reinforcement under the action of corrosion factor so as to improve the obtuse environment on the surface of rebar in concrete [17].

Ghods used X-ray photoelectron spectroscopy (XPS) to study the passive oxide film of carbon steel in saturated calcium hydroxide solution and the effect of chloride on the film properties showing that chloride exposure decreased the thickness of the oxide films and changed their stoichiometry such that near the film/substrate interface $\mathrm{Fe}^{3+} / \mathrm{Fe}^{2+}$ ratio increased.

In this paper, the key factors influencing the passive film structure of the surface of rebar in concrete are taken as the starting points, and the composition and microstructure characteristics of the corrosion on the surface of the rebar 
TABLE 1: The ratio of simulated concrete pore solution.

\begin{tabular}{lcccc}
\hline Species & \multicolumn{3}{c}{ Uncarbonized simulated pore solution } & Carbonized simulated pore solution \\
\hline Reagents & $\mathrm{Ca}(\mathrm{OH})_{2}$ & $\mathrm{NaOH}$ & $\mathrm{KOH}$ & $\mathrm{Na}_{2} \mathrm{CO}_{3}$ \\
$\mathrm{Mol} / \mathrm{L}$ & 0.001 & 0.2 & 0.6 & 0.0015 \\
\hline
\end{tabular}

are studied under the action of carbonation and chloride corrosion so as to provide the theoretical basis to improve the corrosion resistance of steel through optimizing the composition of the steel surface oxide layer.

\section{Experiment}

2.1. Materials and Specimen Preparation. The $10 \mathrm{~mm}$ diameter steel bars are cut into $2 \mathrm{~mm}$ steel thin section, which are polished with 400-mesh, 500-mesh, and 800-mesh sandpaper, wiped clean with $95 \%$ alcohol, and placed in a desiccator for rusting X-ray photoelectron spectroscopy (XPS) analysis. Three simulated concrete pore solution environments were used. Table 1 shows the composition of the precarbonized concrete pore solution and the simulated carbonated concrete pore solution. Test was divided into three groups' preparation: (1) 3\% sodium chloride is mixed with the concrete hole solution to simulate the chloride salt corrosion environment; (2) pore solution is carbonized to simulate a carbonized corrosive environment; (3) carbonation hole solution was performed by adding 3\% sodium chloride to simulate the carbonation and chloride salt composite corrosion environment [18].

Pour $300 \mathrm{ml}$ of the three prepared simulated concrete hole solutions into three covered glass flasks, placing two steel thin sections in each of the glass flasks and tightening the cap. After six months, the steel thin section was removed from the solution, rinsed with deionized water and acetone, and then blown dry with argon and stored in an Ar-filled container. The samples were determined by X-ray diffraction analysis and $\mathrm{X}$-ray photoelectron spectroscopy within two hours.

\subsection{Instruments}

X-Ray Photoelectron Spectroscopy (XPS). XPS used Mg target, $\mathrm{X}$-ray emission current of $20 \mathrm{~mA}$, high-voltage $\mathrm{X}$-ray source $10 \mathrm{kV}$, doubler voltage $2.8 \mathrm{kV}$, full spectrum energy $100 \mathrm{eV}$, and semispectral energy $50 \mathrm{eV}$. Scan was performed 20 times; each step time was $10 \mathrm{~ms}$. $\mathrm{Ar}^{+}$was sputtered $5 \mathrm{~s}$ before each test starting so as to remove the effects of surface contaminants. The sputtering speed of $\mathrm{Ar}^{+}$is about $3 \mathrm{~nm} / \mathrm{min}$. The data was subjected to fractional fitting analysis using CasaXPS 2.3.16 after XPS testing at $0 \mathrm{~nm}$ and $5 \mathrm{~nm}$. The peak curves for all elements are calibrated with $\mathrm{C} 1 \mathrm{~s}$, with a binding energy of $284.6 \mathrm{ev}$.

X-Ray Diffractometer (XRD), D8 Advance Davinci from Bruker, Germany, was used. Using $\mathrm{Cu}$ and $\mathrm{K} \alpha 1$ ray, the tube voltage is $40 \mathrm{Kv}$; the tube current is $40 \mathrm{~mA}$. Continuous scanning was performed with a scan range of $20^{\circ}$ to $70^{\circ}$, a scan rate of $8^{\circ} / \mathrm{min}$, and a step size of $0.02^{\circ}$.

\section{Analysis and Discussion}

3.1. XPS Analysis of Steel Corrosion Products. Figure 1 shows the XPS full scan spectra of steel bar corroded after 6 months of immersion in various simulated corrosion hole solutions. The main components of steel bar corroded in the hole solution are iron, oxygen, carbon, and chlorine. Among them, oxygen, carbon, and iron peak are strong, indicating that the chemical composition of corrosion is mainly iron oxide.

There is no carbon peak in the simulated chloride salt solution, while the peak of carbon in Figure 1(a) is very strong. On the one hand, carbon comes from the steel itself and on the other hand it comes from the dissolution of carbon dioxide during the test. The Fe $2 \mathrm{p}$ binding energy of steel corroded in the simulated chloride salt solution was $709.96 \mathrm{ev}$, the Fe 2p binding energy of the steel corroded in the simulated carbonation solution was $710.76 \mathrm{ev}$, and the binding energy of $\mathrm{Fe} 2 \mathrm{p}$ in the simulated carbonation and chloride salt solution was $711.30 \mathrm{ev}$. This shows that in these three solutions the components of steel corrosion are iron oxide, but the specific composition is different. From simulated chloride salt solution to simulated carbonation solution and then to the simulated carbonization and chloride salt composite solution, the peak value of Fe in steel corrosion products gradually increases, indicating that the content of iron oxide gradually increases and the corrosion of steel reinforcement becomes more serious. The Fe $2 p$ orbital has a bimodal structure due to the splitting of the spin into two energy levels (i.e., Fe 2 p $1 / 2$ and Fe 2 p 3/2). The corrosive iron compounds can be divided into four classes of $\mathrm{Fe}-1, \mathrm{Fe}-$ 2, $\mathrm{Fe}-3$, and $\mathrm{Fe}-4$, corresponding to elemental $\mathrm{Fe}, \mathrm{Fe}_{3} \mathrm{O}_{4} / \mathrm{FeO}$ $\left(\mathrm{Fe}^{2+}\right), \mathrm{Fe}_{2} \mathrm{O}_{3} / \mathrm{FeOOH}\left(\mathrm{Fe}^{3+}\right)$, and $\mathrm{FeCl}_{3}\left(\mathrm{Fe}^{3+}\right)$. The XPS peak fitting of the Fe element of the steel bar corroded after immersing the steel bar in different simulated hole solution for 6 months is shown in Figure 2.

The peak curves of $\mathrm{Fe} 2 \mathrm{p}$ in the simulated corrosion of chloride salt solution fit four peak curves, and the corresponding compounds are $\mathrm{FeO}$ and $\mathrm{FeOOH}$, respectively. By fitting, it can be concluded that the binding energy of the peak position and curve peak area of Fe element in corrosion solution of steel bar in chloride salt solution are shown in Table 2, the relative content of $\mathrm{FeO}$ is $32.3 \%$, and the relative content of $\mathrm{FeOOH}$ is $67.7 \%$.

The peak curves of $\mathrm{Fe} 2 \mathrm{p}$ in the simulated carbonation solution fit three peak curves, and the corresponding compounds are $\mathrm{Fe}_{3} \mathrm{O}_{4}$ and $\mathrm{FeOOH}$, respectively. By fitting, it can be concluded that the binding energy of the peak position and curve peak area of Fe element in corrosion solution of steel bar in chloride salt solution are shown in Table 3, the relative content of $\mathrm{Fe}_{3} \mathrm{O}_{4}$ is $39.9 \%$, and the relative content of $\mathrm{FeOOH}$ is $60.1 \%$. 


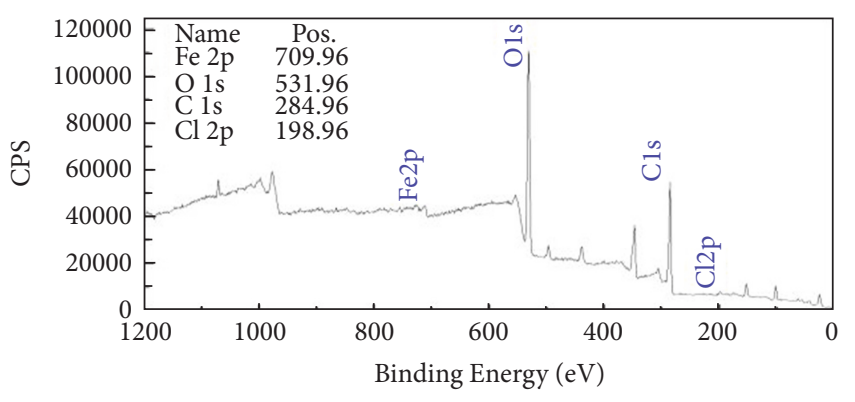

(a) Chloride salt solution

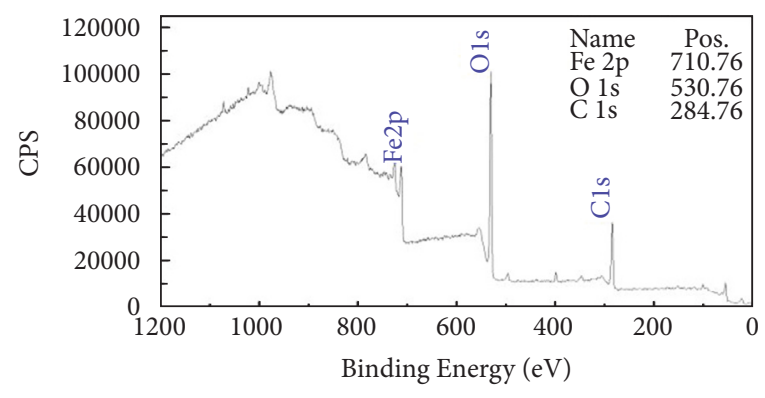

(b) Carbonized pore solution

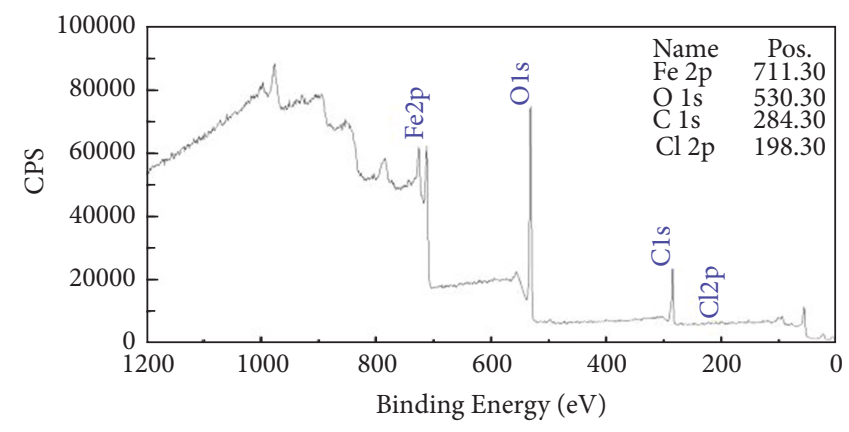

(c) Carbonization and chloride salt composite pore solution

FIGURE 1: XPS full scanning diagrams of reinforcement corrosion in simulated solutions.

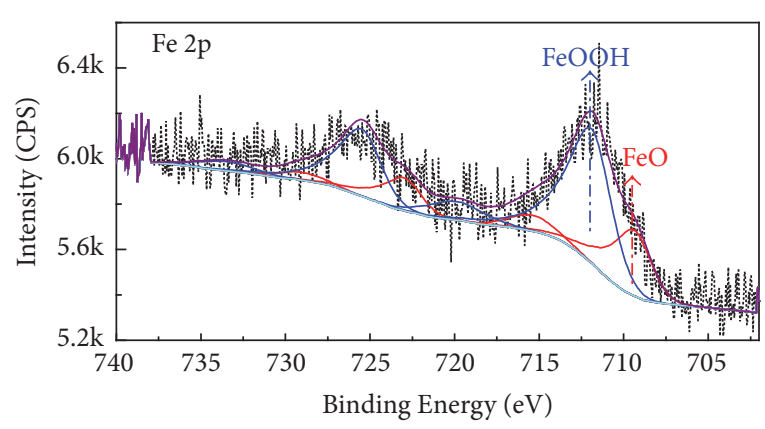

(a) Chloride salt solution

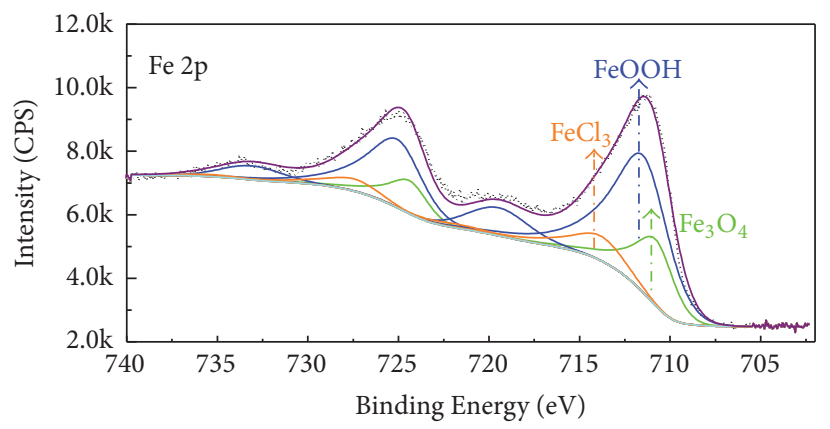

(b) Carbonized pore solution

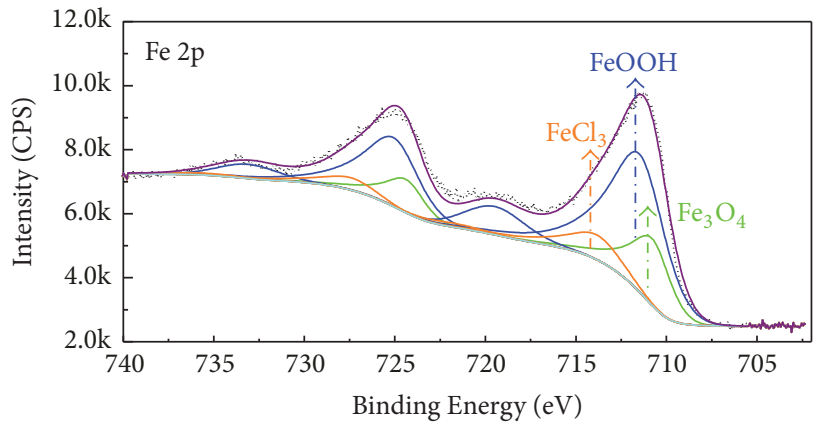

(c) Carbonization and chloride salt composite pore solution

FIGURE 2: XPS scanning diagrams of Fe element in simulated solutions.

The peak curves of Fe $2 \mathrm{p}$ in carbonization and chloride salt composite pore solution fit five peak curves, and the corresponding compounds are $\mathrm{Fe}_{3} \mathrm{O}_{4}, \mathrm{FeOOH}$, and $\mathrm{FeCl}_{3}$, respectively. By fitting, it can be concluded that the binding energy of the peak position and curve peak area of Fe element in corrosion solution of steel bar in chloride salt solution are 
TABLE 2: XPS scanning data of Fe element in the simulate chloride salt solution.

\begin{tabular}{|c|c|c|c|c|c|}
\hline Ingredient & Energy level of $\mathrm{Fe} 2 \mathrm{p}$ & Binding energy of peak position & Half width & Peak area & Relative content \\
\hline \multirow{4}{*}{$\mathrm{FeO}$} & $\mathrm{Fe} 2 \mathrm{p} 3 / 2$ & $709.4 \mathrm{ev}$ & 2.71 & 2037.3 & \multirow{4}{*}{$32.3 \%$} \\
\hline & $\mathrm{Fe} 2 \mathrm{p} 1 / 2$ & $723 \mathrm{ev}$ & 2.71 & 1024.3 & \\
\hline & $\mathrm{Fe} 2 \mathrm{p} 3 / 2$ & $715.4 \mathrm{ev}$ & 3.9 & 893.8 & \\
\hline & $\mathrm{Fe} 2 \mathrm{p} 1 / 2$ & $729 \mathrm{ev}$ & 3.9 & 449.2 & \\
\hline \multirow{4}{*}{$\mathrm{FeOOH}$} & $\mathrm{Fe} 2 \mathrm{p} 3 / 2$ & $711.9 \mathrm{ev}$ & 2.4 & 6215 & \multirow{4}{*}{$67.7 \%$} \\
\hline & Fe $2 p 1 / 2$ & $725.5 \mathrm{ev}$ & 2.4 & 3125 & \\
\hline & $\mathrm{Fe} 2 \mathrm{p} 3 / 2$ & $719.9 \mathrm{ev}$ & 3.14 & 196.9 & \\
\hline & $\mathrm{Fe} 2 \mathrm{p} 1 / 2$ & $733.5 \mathrm{ev}$ & 3.14 & 99 & \\
\hline
\end{tabular}

TABLE 3: XPS scanning data of Fe element in the simulate carbonized solution.

\begin{tabular}{lccccc}
\hline Ingredient & Energy level of Fe 2p & Binding energy of peak position & Half width & Peak area & Relative content \\
\hline \multirow{2}{*}{$\mathrm{Fe}_{3} \mathrm{O}_{4}$} & $\mathrm{Fe} 2 \mathrm{p} 3 / 2$ & $710.8 \mathrm{ev}$ & 2.3 & 825.7 & $39.9 \%$ \\
\hline \multirow{3}{*}{$\mathrm{FeOOH}$} & $\mathrm{Fe} 2 \mathrm{p} 1 / 2$ & $724.4 \mathrm{ev}$ & 2.3 & 2.4 & 1120.1 \\
& $\mathrm{Fe} 2 \mathrm{p} 3 / 2$ & $711.5 \mathrm{ev}$ & 2.4 & 206.6 & 1336.9 \\
& $\mathrm{Fe} 2 \mathrm{p} 1 / 2$ & $725.1 \mathrm{ev}$ & 3.14 & $60.1 \%$ \\
\hline
\end{tabular}

TABLE 4: XPS scanning data of Fe in the combined effect of carbonation and chloride salt.

\begin{tabular}{|c|c|c|c|c|c|}
\hline Ingredient & Energy level of Fe $2 p$ & Binding energy of peak position & Half width & Peak area & Relative content \\
\hline \multirow{2}{*}{$\mathrm{Fe}_{3} \mathrm{O}_{4}$} & $\mathrm{Fe} 2 \mathrm{p} 3 / 2$ & $710.8 \mathrm{ev}$ & 2.3 & 906.7 & \multirow{2}{*}{$19.3 \%$} \\
\hline & Fe 2p1/2 & $724.4 \mathrm{ev}$ & 2.3 & 305.1 & \\
\hline \multirow{4}{*}{$\mathrm{FeOOH}$} & Fe $2 p 3 / 2$ & $711.5 \mathrm{ev}$ & 2.4 & 2230.6 & \multirow{4}{*}{$69.1 \%$} \\
\hline & $\mathrm{Fe} 2 \mathrm{p} 1 / 2$ & $725.1 \mathrm{ev}$ & 2.4 & 312.3 & \\
\hline & $\mathrm{Fe} 2 \mathrm{p} 3 / 2$ & $719.5 \mathrm{ev}$ & 3.14 & 2323.1 & \\
\hline & $\mathrm{Fe} 2 \mathrm{p} 1 / 2$ & $733.1 \mathrm{ev}$ & 3.14 & 343.1 & \\
\hline \multirow{4}{*}{$\mathrm{FeCl}_{3}$} & $\mathrm{Fe} 2 \mathrm{p} 3 / 2$ & $713.9 \mathrm{ev}$ & 2.7 & 409.9 & \multirow{4}{*}{$11.6 \%$} \\
\hline & $\mathrm{Fe} 2 \mathrm{p} 1 / 2$ & $727.5 \mathrm{ev}$ & 2.7 & 102.4 & \\
\hline & $\mathrm{Fe} 2 \mathrm{p} 3 / 2$ & $721.9 \mathrm{ev}$ & 3.2 & 468.4 & \\
\hline & $\mathrm{Fe} 2 \mathrm{p} 1 / 2$ & $735.5 \mathrm{ev}$ & 3.2 & 130.3 & \\
\hline
\end{tabular}

shown in Table 4, the relative content of $\mathrm{Fe}_{3} \mathrm{O}_{4}$ is $19.3 \%$, the relative content of $\mathrm{FeOOH}$ is $69.1 \%$, and the relative content of $\mathrm{FeCl}_{3}$ is $11.6 \%$.

3.2. XRD Analysis of Corroded Steel. Reinforced corroded surface with 5000 times magnification of the scanning electron microscope (SEM) and corresponding corrosive X-ray diffraction spectrum (XRD) after immersing for 6 months in the chloride salt simulated pore solution is shown in Figure 3(a). Most of the surface of the reinforced concrete in the simulated chloride salt solution is not corroded, and the surface is relatively flat and locally convex, indicating that part of the surface is covered with corrosives and the corrosion layer is a thin layer. The steel surface enlarged $5 \mathrm{~K}$ times and holes were found in some places, indicating the passivation film of the reinforcing steel in the simulated concrete pore solution is slowly penetrated by chloride ions and begins to corrode. Analysis by JADE6.5 software shows that there are two clear main peaks at $44.6^{\circ}$ and $64.9^{\circ}$ in $2 \theta$ of steel of chloride salt solution. The results show that there are many noncorroded areas in the simulated salt solution of chloride salt. Compared with other standard cards, it is found that the corrosion products in this solution are mainly $\mathrm{FeOOH}$ and $\mathrm{FeO}$, which is consistent with the results of the previous XPS analysis.

Reinforced corroded surface with 5000 times magnification of the scanning electron microscope (SEM) and corresponding corrosive X-ray diffraction spectrum (XRD) after immersing for 6 months in the simulation of carbide pore solution is shown in Figure 3(b). Steel surface generated a yellow-black rust, but the surface is relatively smooth, with no rust protrusions. The steel surface enlarged $5 \mathrm{~K}$ times and it was found that reinforced steel surface has been corroded and loose porous, with stick shape, and there are three clear main peaks at $36.8^{\circ}, 44.7^{\circ}$, and $65.1^{\circ}$ in $2 \theta$ of steel. Compared with the XRD standard card, the main diffraction peak of $\mathrm{Fe}_{3} \mathrm{O}_{4}$ was found, and the diffraction peak of the simple Fe was not found. Compared with Figure 3(a), 

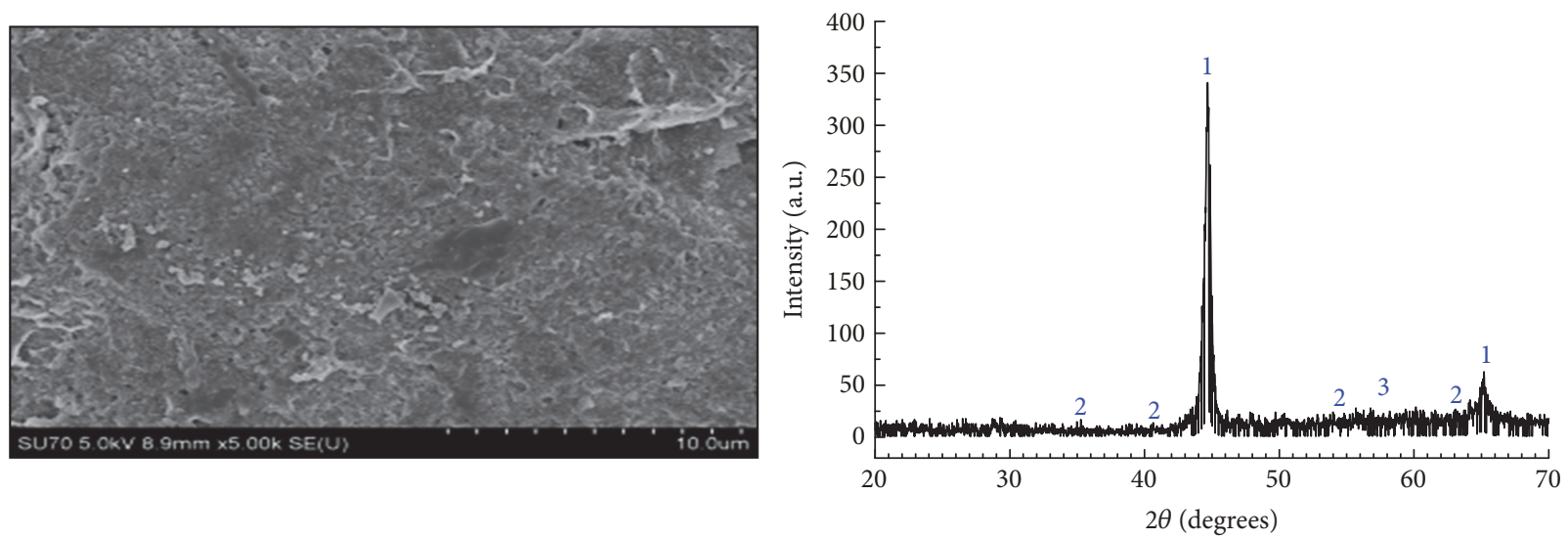
(1) $\mathrm{Fe}$
(2) $\mathrm{FeOOH}$
(3) $\mathrm{FeO}$

(a) Chloride salt solution
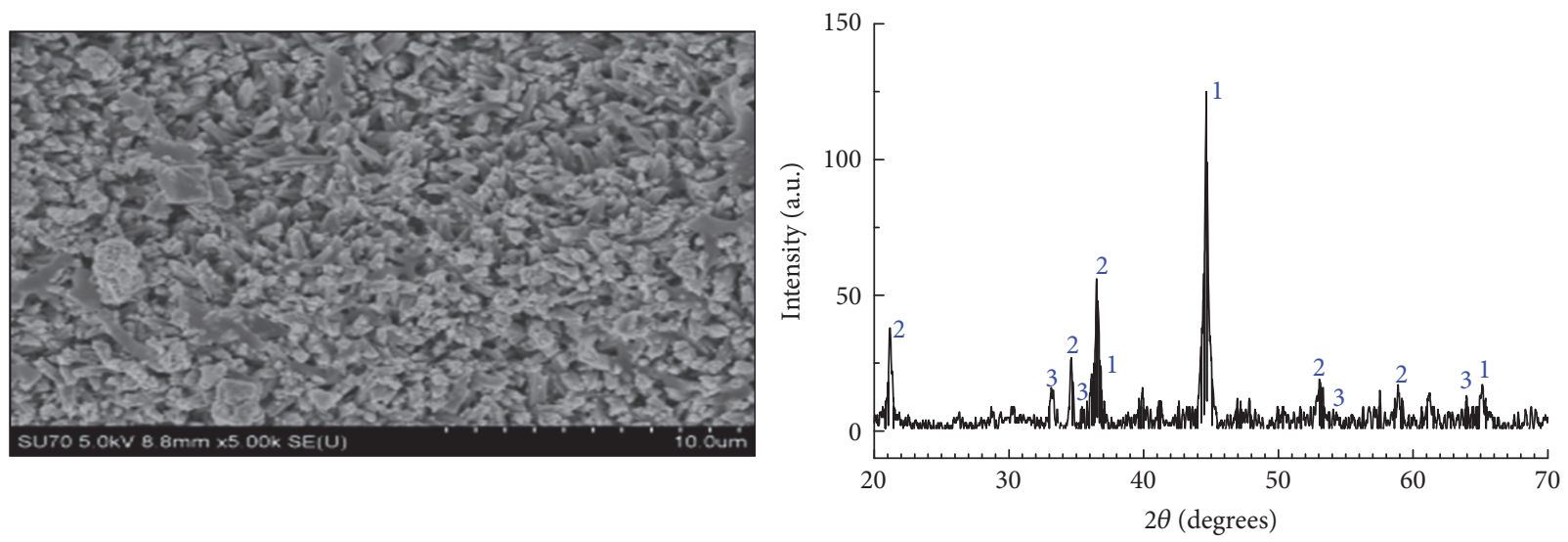

(1) $\mathrm{Fe}_{3} \mathrm{O}_{4}$

(2) $\mathrm{FeOOH}$

(3) $\mathrm{Fe}_{2} \mathrm{O}_{3}$

(b) Carbonized pore solution
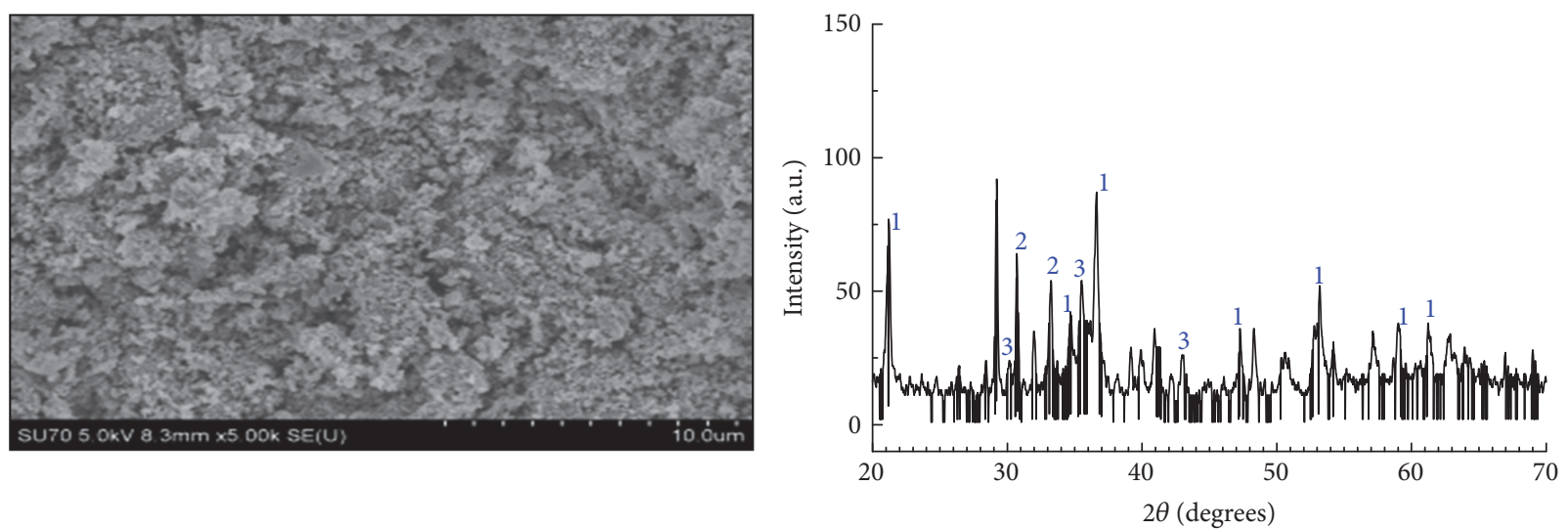

(1) $\mathrm{FeOOH}$

(2) $\mathrm{FeCl}_{3}$

(3) $\mathrm{Fe}_{3} \mathrm{O}_{4}$

(c) Carbonization and chloride salt composite pore solution

FIGURE 3: Morphology and composition of corroded surface of steel bar. 
there were other minor peaks. This shows that the surface of the rebar immersed in the simulation of carbide pore solution has been completely corroded with the formation of $\mathrm{FeOOH}$ and $\mathrm{Fe}_{2} \mathrm{O}_{3}$, which is a good supplement to XPS analysis.

Reinforced corroded surface with 5000 times magnification of the scanning electron microscope (SEM) and corresponding corrosive X-ray diffraction spectrum (XRD) after immersing for 6 months in carbonation and chloride salt composite pore solution is shown in Figure 3(c). The corroded steel bars are brown in color and are in the shape of a layer with uneven thickness distribution and spalling phenomenon. The peak value of the corrosion products is conspicuous with respect to Figures 3(a) and 3(b). The main diffraction peak compared with the standard card shows $\mathrm{FeOOH}$, subpeak was found in $\mathrm{FeCl}_{3}$ and $\mathrm{Fe}_{3} \mathrm{O}_{4}$ in the corrosion, and the intensity has been enhanced. This shows that the corrosion of reinforcing steel is more serious under the condition of chloride salt and carbonized composite, which is consistent with the result of XPS analysis.

\section{Conclusion}

(1) Steel passivation film and rust coexist in chloride salt simulated concrete pore solution, the surface state is more dense, and the main components of corrosion are $\mathrm{FeOOH}$ and $\mathrm{FeO}$. Being reinforced with yellow and black rust corrosion and loose porous in the simulation of carbide pore solution, the main ingredients are $\mathrm{FeOOH}, \mathrm{Fe}_{3} \mathrm{O}_{4}$, and $\mathrm{Fe}_{2} \mathrm{O}_{3}$.

(2) There is a lot of brown rust on the surface of the corrosive and the surface of corrosive was exfoliated in carbonation and chloride salt composite pore solution. The main components are $\mathrm{FeOOH}, \mathrm{Fe}_{3} \mathrm{O}_{4}$, and $\mathrm{FeCl}_{3}$, where $\mathrm{FeOOH}$ content is more than $60 \%$.

(3) The ratio of $\mathrm{Fe}^{3+} / \mathrm{Fe}^{2+}$ increases as chloride ions increase or carbonization increases. And the ratio is maximum under the combined action of chloride ion and carbonization.

\section{Conflicts of Interest}

The authors declare that they have no conflicts of interest.

\section{Acknowledgments}

This work was sponsored by the National Natural Science Foundation of China $(51478227,51778302)$ and by K. C. Wong Magna Fund in Ningbo University.

\section{References}

[1] A. Poursaee, "Temperature dependence of the formation of the passivation layer on carbon steel in high alkaline environment of concrete pore solution," Electrochemistry Communications, vol. 73, pp. 24-28, 2016.

[2] A. Scott and M. G. Alexander, "Effect of supplementary cementitious materials (binder type) on the pore solution chemistry and the corrosion of steel in alkaline environments," Cement and Concrete Research, vol. 89, pp. 45-55, 2016.

[3] R. Liu, L. Jiang, J. Xu, C. Xiong, and Z. Song, "Influence of carbonation on chloride-induced reinforcement corrosion in simulated concrete pore solutions," Construction and Building Materials, vol. 56, pp. 16-20, 2014.

[4] T. V. Shibaeva, V. K. Laurinavichyute, G. A. Tsirlina, A. M. Arsenkin, and K. V. Grigorovich, "The effect of microstructure and non-metallic inclusions on corrosion behavior of low carbon steel in chloride containing solutions," Corrosion Science, vol. 80, pp. 299-308, 2014.

[5] Y. Wang, S. Nanukuttan, Y. Bai, and P. A. M. Basheer, "Influence of combined carbonation and chloride ingress regimes on rate of ingress and redistribution of chlorides in concretes," Construction and Building Materials, vol. 140, pp. 173-183, 2017.

[6] T. Bellezze, G. Roventi, E. Barbaresi, N. Ruffini, and R. Fratesi, "Effect of concrete carbonation process on the passivating products of galvanized steel reinforcements," Materials and Corrosion, vol. 62, no. 2, pp. 155-160, 2011.

[7] H. Luo, H. Su, C. Dong, and X. Li, "Passivation and electrochemical behavior of $316 \mathrm{~L}$ stainless steel in chlorinated simulated concrete pore solution," Applied Surface Science, vol. 400, pp. 38-48, 2017.

[8] J. Williamson and O. B. Isgor, "The effect of simulated concrete pore solution composition and chlorides on the electronic properties of passive films on carbon steel rebar," Corrosion Science, vol. 106, pp. 82-95, 2016.

[9] H. B. Gunay, P. Ghods, O. B. Isgor, G. J. C. Carpenter, and X. Wu, "Characterization of atomic structure of oxide films on carbon steel in simulated concrete pore solutions using EELS," Applied Surface Science, vol. 274, pp. 195-202, 2013.

[10] A. S. Yaro, K. R. Abdul-Khalik, and A. A. Khadom, "Effect of $\mathrm{CO} 2$ corrosion behavior of mild steel in oilfield produced water," Journal of Loss Prevention in the Process Industries, vol. 38, pp. 24-38, 2015.

[11] E. Sosa, R. Cabrera-Sierra, M. T. Oropeza et al., "Electrochemically grown passive films on carbon steel (SAE 1018) in alkaline sour medium," Electrochimica Acta, vol. 48, no. 12, pp. 16651674, 2003.

[12] Y. Tang, S. Wang, Y. Xu, and J. Ni, "Influence of calcium nitrite on the passive films of rebar in simulated concrete pore solution," Anti-Corrosion Methods and Materials, vol. 64, no. 3, pp. 265-272, 2017.

[13] A. Alhozaimy, R. R. Hussain, A. Al-Negheimish, R. Al-Zaid, and D. D. N. Singh, "Effect of simulated concrete pore solution chemistry, chloride ions, and temperature on passive layer formed on steel reinforcement," ACI Materials Journal, vol. 111, no. 4, pp. 411-421, 2014.

[14] Y. Zhou and Y. Zuo, "Surface films on plasma nitrided stainless steel subjected to passivation treatments," Applied Surface Science, vol. 353, pp. 924-932, 2015.

[15] J. Z. Liu, W. Sun, J. B. Chen et al., "Carbonation rate and microstructural characteristics of hardened cement paste with high alkali content," Journal of the Chinese Ceramic Society, vol. 42, no. 7, pp. 1005-1010, 2014.

[16] P. Ghods, O. B. Isgor, J. R. Brown, F. Bensebaa, and D. Kingston, "XPS depth profiling study on the passive oxide film of carbon steel in saturated calcium hydroxide solution and the effect of chloride on the film properties," Applied Surface Science, vol. 257, no. 10, pp. 4669-4677, 2011. 
[17] R. Blair, B. Pesic, J. Kline, I. Ehrsam, and K. Raja, “Threshold chloride concentrations and passivity breakdown of rebar steel in real concrete solution at different $\mathrm{pH}$ conditions with the addition of glycerol," Acta Metallurgica Sinica (English Letters), vol. 30, no. 4, pp. 376-389, 2017.

[18] J. Liu, M. Ba, Y. Du, Z. He, and J. Chen, "Corrigendum to "Effects of chloride ions on carbonation rate of hardened cement paste by X-ray CT techniques" [Constr. Build. Mater. 122 (2016) 619-627]," Construction and Building Materials, vol. 131, p. 800, 2017. 


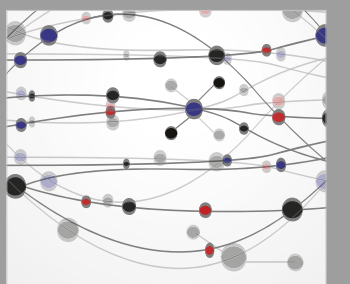

The Scientific World Journal
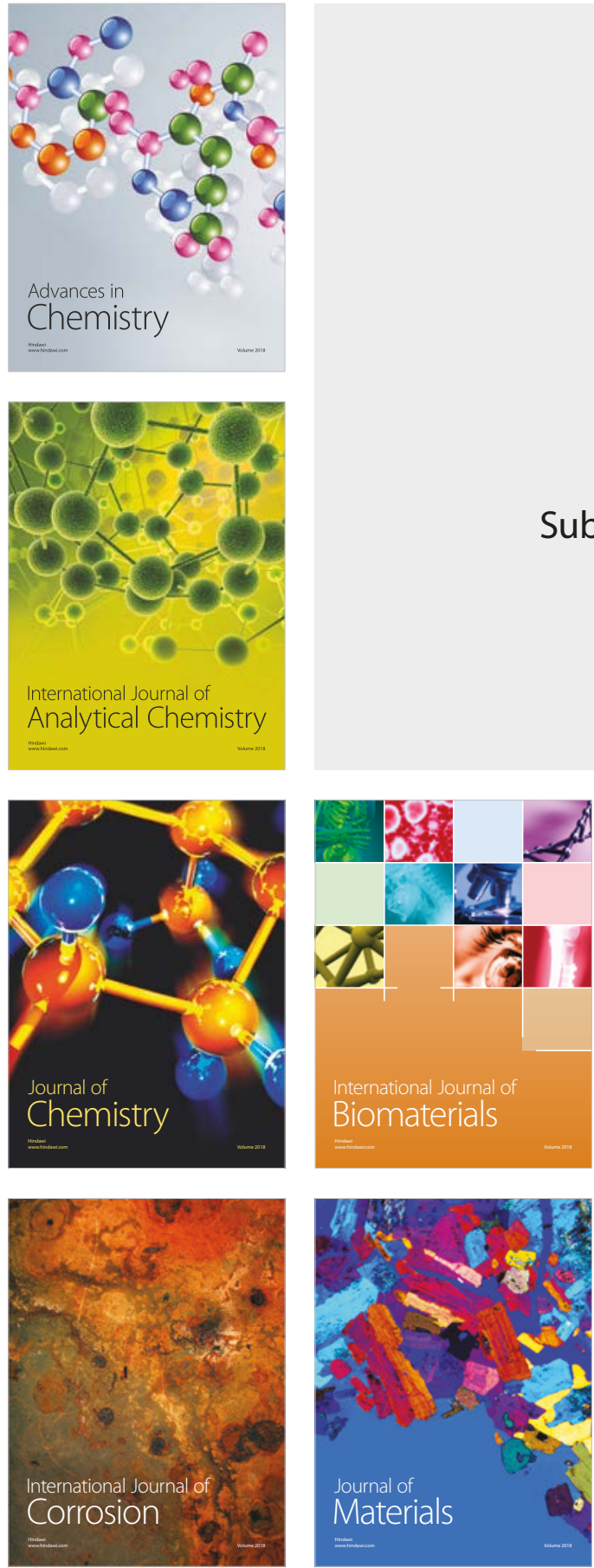

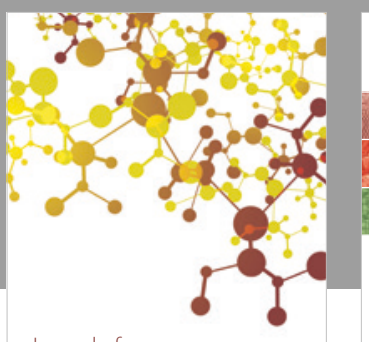

Journal of

Applied Chemistry
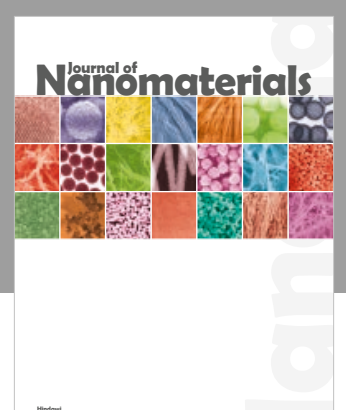

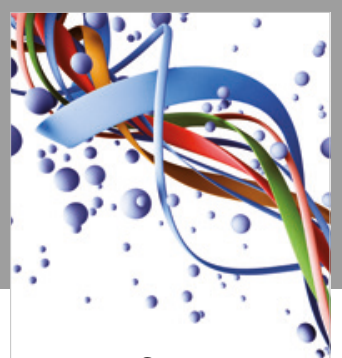

Scientifica

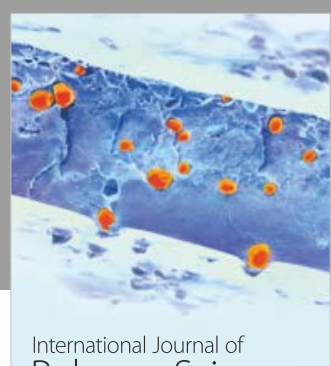

Polymer Science

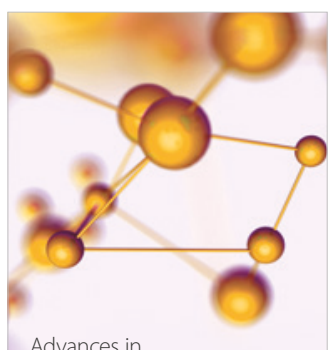

Physical Chemistry
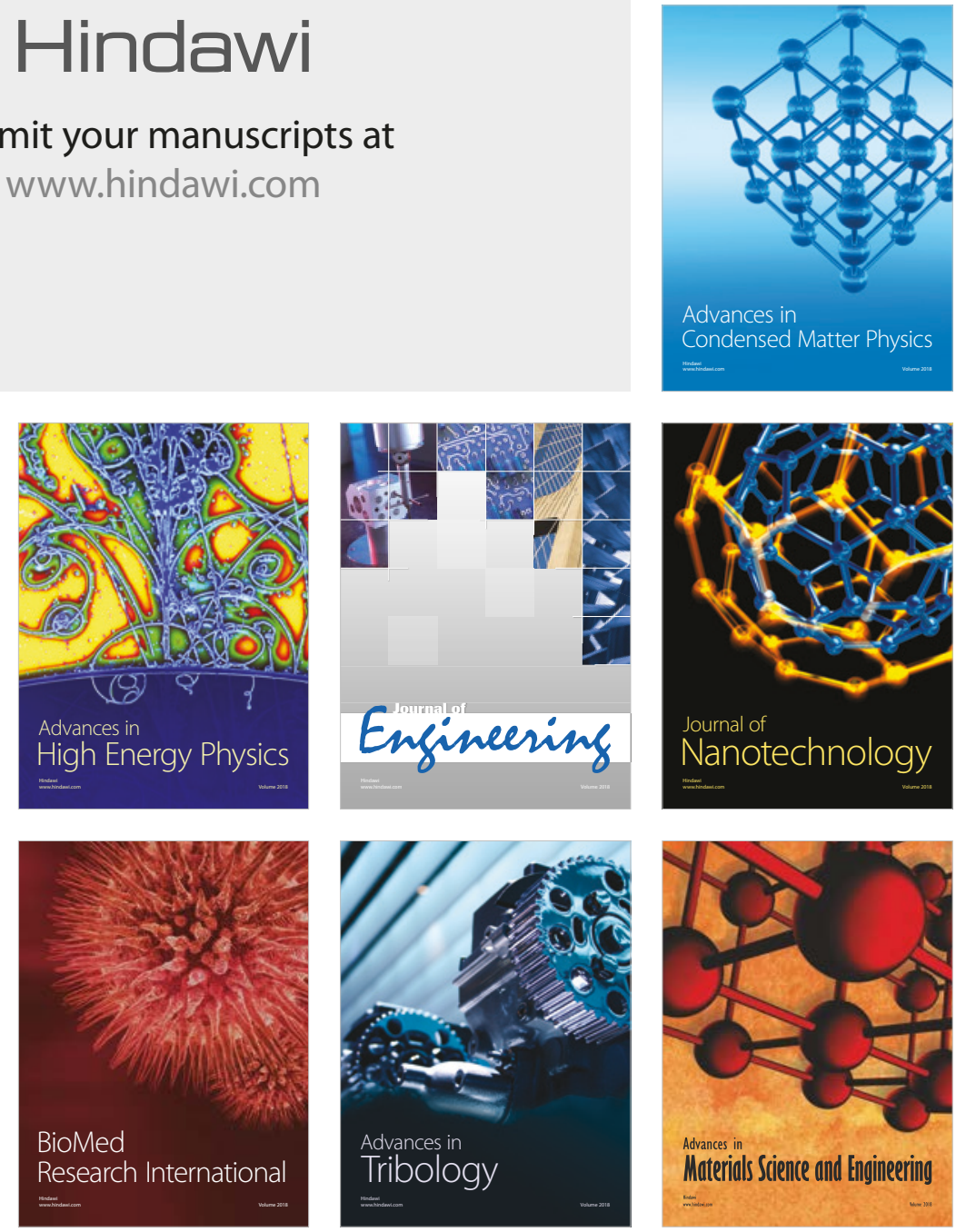